\title{
Introduction: the design concept - anything, everything, something or nothing
}

Kirsten Marie Raahauge,

The Royal Danish Academy of Fine Arts

This volume of Artifact explores the design concept. It is concerned with the differences and similarities that exist in the various interpretations of design. The effort is not to try to define the concept or to state what is right or wrong in the confusing jungle of interpretations; rather this is an effort to understand some of the ways in which the concept is used, and what this means for the praxis of designers and the development of the field of design in its widespread forms.

The basic premise behind this volume is that the design concept is dependent on its various contexts, both the internal contexts of the variety of specializations of design and the external societal contexts. This issue is concerned with the floating and reflexive nature of the design concept; different contexts position it in ever changing new roles, and these changes are mirrored in everyday practice, both by way of how we use design and through designers' practice.

Within the last couple of decades, design has become a rather broad concept, dealing with extra-material sides of life, such as social behavior, cultural ideas, psychological and cognitive stereotypes, experience design, emotional design, or even mind design. This shows the huge impact of design in today's society, both as a profession and as a field of knowledge, but at the same time, the lack of boundaries might also be seen as a sign of crisis. Design is surely an expanding field, but in the same movement it might also become a vaporizing field. This might give rise to yet another motion, namely a condensation of design in new fields, while other areas might become less defined by design. In other words, a redistribution of the meaning of design might be taking place in these years.
This issue explores the design concept in relation to different concrete fields of practice and thereby adds to the discussion of the broader, vaporizing, condensing, redistributed or otherwise changing design concept.

\section{EXPANDING OR IMPLODING FIELDS OF DESIGN?}

The point of departure for this anthology is The Royal Danish Academy of Fine Arts (KADK). At KADK, the design concept always means something, although its meaning varies at the different parts of the school: Industrial designers differ from communication designers; fashion designers find similarities when comparing their design methods with architects, etc. The different conceptions of design make it difficult to reach common ground in practice, research, and teaching. We have felt the need to examine the situation in the form of a publication; possibly, also leading to further explorations of the field.

This situation seems to be widespread, possibly global. In the beginning of the 2000s the graphic designer Bruce Mau formulated a hypothetical endpoint of this trajectory by stating the rather radical opinion that design is everything. Today it is easy to find quotes on the Internet representing his view on the design concept:

\section{No longer associated simply with objects and appearances, design is increasingly under- stood in a much wider sense as the human ca- pacity to plan and produce desired outcomes. Bruce Mau, 2007 (http://defining-design.net/ learn/definitions-explained//)}

This broad understanding of the concept has become common, making older definitions of design as, for example, an applied art seem somewhat antiquated. However, if design has become equivalent to "plan," is it possible to talk about a discipline? With 
these thoughts, we sent out a call for contributions asking for critical, contradictory, or complementary takes on Mau's approach.

The central question seemed to be whether design means anything when claimed to be everything? It might be exactly through its expansion that the concept and the discipline could implode into nothing. Another scenario could be that design has become an archipelago of design concepts so vast that we might talk about different disciplines working in different ways. If we chose this approach to the concept, it might be relevant to ask whether these different design practices and discussions have something in common.

Starting with the urge to publish an educational book and to discuss the concept from the designers' point of view, this issue is the first step in an exploration of the design concept that might eventually lead to other publications of educational, praxis-oriented as well as academic genres. Seven articles were published in this issue of Artifact in 2015. Now, in 2016, the last articles have been published, and The Design Concept has reached its final shape. The contributions are rather different in their form, reaching from classical academic papers to explorative articles, from praxis-oriented analyses to theoretical discussions. This diversity has been vital for the editors, since we wish to include articles with a personal and praxis-oriented perspective on the topic as well as traditional academic papers.

\section{CONTEXTS}

In a floating world where the inwards fields of design are merging and the societal contexts from the outside are changing, the huge amount of ideas about design cannot be pinned down to one or more definitions. Instead, the challenge might be approached in another way:

Do not search for a definition, search for contexts.

The outwards contexts of globalization and localization, of new technologies, of rapid growth of cities, and a similarly rapid implosion of other places are of course important, and they can further be understood through the perspectives of the development of the different states regulating design, of the consumer society and neoliberal economy framing the production of design worldwide, and of the organization of communities in different parts of the world. Furthermore, the inward contexts of how you conceive of design in the vast amount of designer communities and schools are connected to historical, societal and cultural contexts. This has to do with our idea of family, home, gender, and age; of the body and the way it should be presented; of work and leisure; of our perception of beauty and ugliness, comfort and the uncanny; etc. Spatial and material contexts are important, having to do with organization of private and public spaces and also with our actions in these spaces, with our perception of things and places, our ideas about nature and culture, and our use of virtual and physical space, etc. Design is also a matter of control, oscillating between offering possibilities by way of design, and restricting by way of design.

Such contexts are exactly what the articles draw upon. They do it in different ways, thus forming a mosaic of approaches, pointing from their disparate positions to the focal point, the design concept.

\section{THE GAZE FROM OUTSIDE: SOCIETY}

A number of articles take their point of departure in the outwards societal contexts that have an impact on how design is perceived. In their article Can Anyone be a designer? Amateurs and Fashion Culture, Maria Mackinney-Valentin and Fabian Holt discuss the implications of recent media evolutions on the conventional roles of the designer with a specific emphasis on fashion culture. They argue that media has become a key context for understanding the relationship between professional designers and amateurs and the evolution of more distributed forms of design creativity. Furthermore, they discuss whether anyone can be a designer in the Do It Yourself-culture that springs from this situation. This change in the role of the designer brings new perspectives to the understanding of the concept of design, and one might ask how design finds its conceptual limitations in an open market of anyone being designers.

In her discussion of the way places in Copenhagen are regarded by their users, Marie Stender also takes her point of departure in the societal framework of design; Copenhagen has undergone major changes as a result of its rapid growth and Stender focuses on residential buildings and neigbourhoods that have been built recently by famed architects. In her article The Overdesigned and the UndesignedPlacemaking in New Residential Complexes, she argues that the residents regard places as something that can be designed, while these designed places at the same time seem to hold a remarkable longing for that which is not designed. Through branding and other strategies to shape identity by way of design, 
contemporary architecture strives to shape not only material places, but also immaterial social and cultural aspects of it. This brings up the question of "who we are" and "what we feel," thus adding a layer to the discussion of interrelationships between design and the society it is framed by. Stenders pointing to the longing for that which is not designed brings up the question of the design concept from a new angle: maybe anyone can be a designer, but the idea of not designed places pushes the discussion in another direction, away from the "anyone"-perspective, to a longing for "no one" to design. This might be immanent in the field of contemporary design; the more possibilities for design to become part of the praxis of anyone, the more you long for a place without the feeling of someone who has designed it for you. The DIY-design might also be more easy to implement into fashion culture than to place making, which might give the longing for design free areas a more prominent role when you explore brand architecture than when you investigate fashion culture.

These discussions might be highlighted from a new angle by Søren Rosenbak, who points to the commonplace description of design as something useful. Where Stender highlights the longing for no design, Rosenbak questions whether design might be better understood through the notions of uselessness and usefulness, and he argues for a useless design practice. In his article Prototyping a Useless Design Practice: What, Why \& How?, he points to the industrial revolution as the start of the discipline, and follows the development up to the Anthropocene. After that, he discusses the neoliberalist growth economy, concluding with a discussion of the usefulness of useless design being its ability to bridge the growing difference between industrial and post-industrial design paradigms. In this way, Rosenbak makes a direct connection from the societal contexts of neoliberalism and post-industrialism to contemporary design strategies.

From this advocacy for useless design as a critique of capitalism, there is a link to Barbara Adler and Pernille Askeruds essay about community based design Design Education for Local Development. Adler and Askerud argue that in the western part of the world the concept of design is increasingly perceived as a central means of how we organize the world and imbue it with (cultural) meaning, rather than a quality attached to material objects. They deal with the societal framework in the form of communities of artisans from five different regions, namely Morocco, India, Thailand, Mexico, and Singapore, and by way of their empirical material from projects in these communities, they unfold a comparative analysis centred around the design concept at work in these contexts, and find a diversity in the interpretation of the concept of design which might be hidden when seen from the Western point of view. Askerud and Adler wish to cast out a paradigm to the fostering of sustainable economic and cultural development in local communities, and they point to a chance for an awareness of the important impact of notions of design in terms of innovation and cultural diversity.

In quite another community, namely the community of moving images, design also plays a major role. In his article Shaping Dreams: Design Ideas and Design Fiction in Movie and Television Production Design, Jakob lon Wille points to the rather large impact design processes have on production on film and television, especially how the narrative and visual approaches of designers are appreciated by filmmakers. Furthermore, Wille argues that the design concept is expanding by way of newer trans-disciplinary developments in design, or rather between the fields of design research and film research. Not only has the design concept expanded to include new areas through this development, but methods within the design discipline are playing a large role in the concrete shaping of movies and television. This brings the argument back to Fabian Holt and Maria Mackinney-Valentin who pointed to media as a key concept for understanding design; here in Jakob Ion Willes article we see that design also becomes a context for media by becoming a co-producer of media and by the expansion of the design concept.

\section{THE GAZE FROM INSIDE: DESIGN SOCIETIES}

The above mentioned articles primarily position themselves outside the design discipline, analysing design and the design concept as seen from positions in society, always in dialogue with design, but with the societal context as the primary context for these approaches. Now we turn to the gaze that looks at the design concept from within the discipline, from the diversity of the design societies.

One of the core issues within the design disciplines is the relationship to art, and hereby the discussion about whether art is embedded in the design concept. This intricate question is taken up by Anders Brix in his article Design and the Function of Art. Here he deals with the apparent dichotomy between art and artefacts inherent in Western thought (here we see a parallel to Adler and Askerud who also operate with the West and the Rest (as Jonathan Friedman put it in 1994, p. 167)). Arts should not 
serve a function except for aesthetic contemplation, while artefacts are functional objects intended for a specific purpose. This art-artefact dichotomy, which is rooted in "function," Brix argues, permeates contemporary design discourse. By way of two examples, and by using Alfred Gell, Brix reveals some of the logical inconsistencies that the dichotomy gives rise to. Furthermore, Brix discusses the difference between words (that separate) and things (which are whole), and how words tend to hide important features of things, and also of the potential of design.

Not only from within, but also from a historical point of view, Sofie Beier deals with the impact of design on the rise of typography as a design discipline with the first known type designer, John Baskerville (1706-1775). In her article The Design Process Seen Through the Eyes of a Type Designer she discusses the differences and similarities of the design processes of Baskerville and those of contemporary type designers. In that way she addresses another vital element of design, namely the question of trans historic elements in design; when is it the same process that travels through time, and when is there something new, even innovative, going on? This also goes for the design concept; to what extent is design a consistent concept through time, how much has altered with the ever changing societal framework the design concept is embedded in?

Katrin Bichler and Sofie Beier focus on design activism in their article Graphic Design for the Real World. Design activism is immanent in contemporary discussions about design and the design concept, but it is also an evergreen as the question about how designers have an impact on the surrounding society is asked with every new generation, thus revitalising the concept of design as well as design praxis with new ideas. In today's design, the question is asked on a background of design being more often than not used for commercial ends. The two visual designers discuss the possibility of designing for "the good cause" in a contemporary setting by way of a variety of examples, and find that the persuasiveness of "good cause"-activism has a limited activist potential and thus social impact. They argue that Papanek as a designer of objects had an impact, while visual communicators cannot work in the same way, since their assignments often come from advertisement companies. On this background, Bichler and Beier argue that designers might not have a large impact by being persuasive, instead they could be informative and thereby, they might be able to intervene into problems on a functional level, similarly to artefacts from design disciplines such as industrial or product design and architecture. Here we see a correspondence to the questions raised by Søren Rosenbak, as both articles address the question of usefulness of design in a consumer economy: the outset of the articles differ, also the line of argument, but they share the concern about how to be a designer in a world haunted by the problems of neoliberal consumer society.

Now, the gaze from outside and the gaze from inside in the above mentioned articles are supplemented with the third kind of gaze; the gaze from above. Some of the articles engage in a meta-discussion of design, not seeing it from a position inside or outside, but rather discussing the design concept from above. All the articles have in them meta-discussions, but the three remaining articles take their explicit point of departure from this position.

\section{THE GAZE FROM ABOVE: META-DISCUSSIONS}

Stephane Vial discusses the design concept by posing the question: What is the essence or quiddity of design? in his article The Effect of Design. A Phenomenological Contribution to the Quiddity of Design Presented in Geometrical Order. Only philosophy of design can answer this question, Vial argues, and by way of 1 overview, 5 definitions, 3 axioms, 3 hypotheses and 3 developments he analyses the question of the essence of design. Vial opposes the idea that everything is design; design cannot do without industry, but industry can easily do without design he states. Furthermore, design is not a being (a space, a product or a service) but an event (the effect of it). This is the ontophanic effect of design. Also design is characterized by its formal beauty, its callimorphic effect, and its reform of social life, its socioplastic effect. By way of this phenomenological triad, Vial discusses the criteria separating design from non-design and points to the effect of design as the intention, which design is working towards. Vial reintroduces a discussion of essence in order to challenge the idea that everything is design; he stresses the reception of design rather than conception of design; and also he puts his phenomenological argument into a strict formal scheme, whereby he succeeds in outlining structural-and-phenomenological delimitations of what can be understood through the design concept and what is non-design.

Per Liljenberg Halstrøm and Per Galle also set out to evaluate the definition of design. In their article Design as Co-Evolution of Problem, Solution, and Audience, they review theories about design as a professional enterprise and focus on the theoretical 
notion of "co-evolution." Although this notion brings them some of the way in regard to understanding design deliberations by dealing with "co-evolution" of problem and solution in design, they find that something is still lacking, the practitioner is still left at a loss for guidance. To remedy this situation, they propose the notion of "triple co-evolution" that also involves the "audience" of a designed artefact. Furthermore, they suggest that "constitutive rhetoric" might offer a valuable resource for conceiving of design in terms of triple co-evolution, since it points to the "audience constitution," i.e., the position offered to the audience of a design product. In this way, Galle and Halstrom discuss the design concept as seen from not only the designers point of view (problem-solution deliberations), but also integrating the position of the audience, thus forming a triad based on both the designer, the product, and his or her audience. Also, Halstrøm and Galle take their departure in design theory while discussing the concept of design.

This is also the case with Jude Chua. In his article Design Without Final Goals: Getting Around Our Bounded Rationality, he discusses different theories of design with a focus on intention and the unintended consequences of one's original design intention. Taking his point of departure in Herbert Simon's theory of design, he shows the theorists and ideas that Simon was inspired by, and discusses the different takes on design, intention, rationality, and unintended consequences of design embedded in these theories. Through this reading of a specific field within design theory, Chua is able to point to an important characteristic of design, namely its ability to work without final goals and thus its potential to open up for worlds that we did not know existed. As Chua writes, the theorists he discusses were all painfully cognizant of the fact that human beings are not as smart as they think they are, and therefore we have to design strategies for outsmarting ourselves. Chua in this article manages to make the double movement of discussing the positions of design theory in order to narrow down some kind of definition of the design concept (the gaze from above), and at the same time pointing at something that escapes this theoretical effort, something that goes beyond: design is characterized by its potential to liberate itself from its own intentions, so to say; it is defined by its ability to integrate unintended consequences as new final goals of one's design.

This issue of Artifact also has two reviews that both discuss the design concept. Many of the arguments and discussions of the articles can also be found in these reviews. Mads Nygaard Folkmann's book
The Aesthetics of Imagination in Design (2013) is reviewed by Susann Vihma, and Anthony Dunne \& Fiona Raby's book Speculative Everything. Design, Fiction, and Social Dreaming (2013) is reviewed by Tau Ulv Lenskjold.

Ivar Tønsberg's photographs of construction sites deal with design from a critical point of view, claiming that construction sites hardly can be seen as works of design; merely they are temporary unavoidable workshops in the process of designing the city. Constantly popping up whenever spaces and places are to change, construction sites can be seen as evanescent places of possibilities and irritating, disturbing erosions of order in the public space. When you consider the representations of planned buildings on billboards and the hoardings hiding the construction sites, the actual construction sites are far from that generic look, which cities, developers, and architects seem to strive to achieve. The construction sites are here seen as pragmatic realities, part of everyday life, coexisting with the constructed parts of the city.

Sometimes a volume of a journal or an anthology is edited so that the articles fit together in ways that the editors think would make an interesting mosaic of interrelated themes. This is not the case with this issue. Therefore, it is both surprising and satisfying when you find that by some lucky strike the articles in fact form such a mosaic of interrelated themes. A possible example of designing without final goals, this issue of Artifact displays an array of interesting discussions of the design concept that supplement, contradict, and support each other in discussing themes of principal character for how to regard the design concept. In that way, by gazing from without, from within, and from above, these articles cover a vast array of positions in the search for an understanding of the design concept.

While acknowledging the importance of the design concept in contemporary society and design societies, it is vital to explore the problems and possibilities arising from the special ways in which ideas about design are folded into different contexts and has an impact on these contexts and their movements. The articles presented in this volume of Artifact ask many intriguing questions and suggest a range of possibilities connected to the concept in different settings. A broad variety of designers from different fields of the design discipline have contributed to the issue, and also a range of design researchers have contributed with their analytical gaze on the field. The issue presents a broad range of design-field specific cases and adjacent 
praxis-based perspectives, enabling discussion of the concept across disciplines. One might find similarities and differences as well as problems and possibilities in the way design and the design concept are approached and contextualised. The articles form a field of new and relevant discussions linking design to the surrounding world, as it will become visible in the following pages.

Friedman, Jonathan. (1994). Cultural identity and global process. London; Thousand Oaks, Calif.: Sage.

\section{CORRESPONDENCE}

\section{Kirsten Marie Raahauge}

Royal Danish Academy of Fine Arts

School of Design

Philip de Langes Allé 10

1435 Copenhagen $\mathrm{K}$

Denmark

E-mail: kmr@kadk.dk

First version published online 28 July, 2015

This version published online 10 0ctober, 2016

http://dx.doi.org/10.14434/artifact.v3i4.19394 